2.

\section{ANGLICAN PARISH OF BLENHEIM: STRENGTHENING TO THE CHURCH OF THE NATIVITY}

C.C. Davidson*

\section{BACKGROUND:}

The Church of the Nativity in Blenheim is in two distinct structural types. The nave, narthex and tower are of brick veneered reinforced concrete and steel portal frames constructed about 1959 to replace an old timber building. Check calculations showed this to generally meet latest code requirements.

The transept and chancel was, prior to the strengthening work, of unreinforced brick masonry built about 1906 - with some reinforced buttresses and reinforced concrete bands. The whole building is roofed with concrete tiles.

The initial assessment of the building was made in terms of Clause $301 \mathrm{~A}$ of the Municipal Corporation Act in 1976.

This building is regarded as one of Blenheim's finest older buildings and the members of the Church did not wish to lose, or detract from, its character, either by obvious strengthening or rebuilding.

\section{STRENGTHENING ALTERNATIVES:}

Various strengthening possibilities were investigated involving combinations of removing brick gables; concrete bands; beams and columns; arch strengthening; bracing and ties: reinforced concrete inner skin; reinforced concrete foundation beams.

After consideration of various proposals and estimates at Vestry and Parishioners meetings it was decided to replace the unreinforced brick section with a new structure.

A basic requirement was that the new structure had to maintain the character of the existing building.

\section{NEW BUILDING PROPOSAL:}

A design was completed using reinforced concrete walls with a steel bracing system. The concrete walls were faced with brick and existing windows reused. The chancel and transepts were reduced in both height and length but the basic shape was retained.

The tenders were higher than the finance available. At this stage, in discussion with I.G. McSaveney, then of Stresscrete Marlborough, the possibility of drilling the walls to provide a viable alternative was first envisaged. As this could provide an unobtrusive strengthening system we were instructed to proceed with the detailed design.

\section{STRENGTHENING PROPOSAL}

\section{General -}

The original intention was to use the drilled holes to stress the walls, but this was abandoned in favour of a system of vertical reinforcing bars.

A complication in most strengthening proposals was the organ opening adjacent to the arch. This was overcome by shifting the organ to a position over the main entrance doors. This not only assisted the strengthening, but also pleased the musicians and allowed use of the organ during the construction work by separating the nave section with a temporary wall.

The weight of the roof also presented design problems. As this had been renewed in 1959 there was a reluctance to meet the cost of replacing it with a lightweight roof.

Design Philosophy and Stresses -

This was based on tests which showed the brickwork and cement mortar to be relatively sound.

The existing roof was sarked and considered satisfactory as a diaphragm. This was to be used where possible in the distribution of loads to other elements resisting lateral forces. All edge diaphragm connections were to be upgraded to ensure an adequate tying action at roof level. Where the diaphragm was neglected in areas of the design, it was assumed to be a secondary 'back-up' system.

Any existing reinforced concrete buttresses and bands were not considered in the design.

Sections of the building were analysed as simply as possible for the design earthquake applied in both directions and the worst design case selected. Simple bending theory was used with all stresses being assessed in the elastic range. The building was also analysed as a unit.

Design stresses for the masonry were as per the British CP 111:1964 "Structural Recommendations for Load Bearing Walls". A basic strength of $10.34 \mathrm{MPa}$ (1500psi) was used which is well within the test results. From $\mathrm{CP} 111$ this gave:

$f$ compressive $=1.03 \mathrm{MPa}$ (under $\mathrm{EQ}=1.37 \mathrm{MPa}$ )

f local bearing $=1.55 \mathrm{MPa}$

Alternatively, from NZS 1900 Chapter 9.2 the walls are generally classified as unreinforced.

Basic allowable stress $1.03 \mathrm{MPa}$

Maximum bending stress

$0.96 \mathrm{MPa}$

after applying reduction factors for Slenderness Ratios in accordance with CP 111. 
Face loads on walls were considered to be resisted in bending with reactions provided at eaves and foundation levels. At the eaves, a strengthening beam would then transmit eaves loadings to end supports, being generally shear walls. Chemical anchors were assessed on a brick "pull-out" basis using an allowable shear on the mortar of $0.2 \mathrm{MPa}$ (from CP 111) and a further factor of safety under earthquake of 2. This gave an allowable load of $6.8 \mathrm{KN}$. Tests showed the "pull-out" basis to be the failure mode, and actual design figures were considerably lower than allowable values.

\section{Design Loading -}

The strengthening work was designed for a seismic coefficient of 0.16 based on Fig. 1 NZSS 1900 Chapter 8 - Public Buildings, and assumed that the heavy roof covering would be replaced with a lightweight material.

The design was later checked for the existing roof and this was found to reduce the seismic coefficient to 0.1 .

NZSS 1900 Chapter 8 was used as Blenheim Borough Council assessments are based on this code.

\section{STRENGTHENING METHODS}

The strengthening method centred around the drilling of vertical holes in the centre of the $343 \mathrm{~mm}$ thick brick walls and grouting in D20 and D16 reinforcing bars.

The walls were supported at ground level by the concrete foundations and at eaves level by a steel framing system fixed to the brickwork with chemical anchors.

The transept gable ends were supported by the roof diaphragm which was assisted by additional bracing.

The walls and arch between the transept and chancel were strengthened with a reinforced concrete infill panel in the organ opening and with a steel supporting system for the arch.

Existing bracing below the ceiling line in the centre of the transept was utilised and the ends of the ring beam system were fixed to the first of the portal frames (1959). Bar ties across the chancel were replaced with heavier members.

The masonry and reinforced concrete walls were utilised as shear walls where required.

\section{CONSTRUCTION ASPECTS:}

\section{Testing -}

Once the initial decision to investigate possible strengthening methods had been made a relatively simple series of tests were conducted to check on the quality of the brickwork.

Core tests were taken from ten locations around the bottom of the wall. Seven of these cores (69mm diameter by $11 \mathrm{~mm}$ high) were crushed and failed at an average stress of $18.5 \mathrm{MPa}$. The mortar was found to be a lime mortar with some cement. It showed reasonable strength and good adhesion to the bricks.

This series of tests proved what had been apparent from a detailed visual examination; namely that the walls had been well constructed of sound materials and were capable of taking the required design loads.

Another series of tests was conducted to determine the pullout capacity of various mechanical and resin capsule anchors in brickwork. Because of the destructive nature of these tests a wall of similar age and construction that was shortly to be demolished was chosen for the tests. These tests proved that Chemset anchors supplied by Ramset were superior to mechanical devices for fixing both bolts and deformed reinforcing bars in the relatively soft brickwork. The tests showed that the anchors pulled the bricks out before the anchor failed.

\section{Hole Alignment}

The critical factors affecting the alignment of the hole are the uniformity of the material being drilled, the ratio of bit diameter to drill stem diameter and the feed rate of the drilling machine. If the machine is accurately set by a skilled operator, a straight and true hole is assured. On this contract sixty nine $56 \mathrm{~mm}$ holes were drilled up to 11.5 metres deep within a tolerance of $+25 \mathrm{~mm}$. Each hole was checked at the bottom by drilling a hole through the foundation to flush out the cuttings prior to grouting.

To achieve this degree of accuracy the drilling subcontractor, Longyear New Zealand Limited, requested a rigid scaffold firmly fixed to the building at all the points to be drilled. They also tested various bit sizes and diamond setting patterns to achieve the required penetration rate and control. Their driller checked the hole alignment constantly for the first $900 \mathrm{~mm}$ of depth. Beyond that depth the drill would continue on the line initially set and could not be altered.

Several minor problems were encountered during drilling. The first of these was the presence of electrical conduits built into the walls. Fortunately these were very old circuits and had long since been by-passed.

The second problem was reinforcing bars in concrete bond beams in the gable ends. These posed a problem for the surface set diamond bits that had proven best in the brickwork and required a switch to impregnated diamond bits when encountered.

The third problem was loose bricks within the walls. These occurred at the corners and were accompanied by some visible cracking on the wall surface. They were probably caused by earthquake 
or settlement induced loads and were overcome by grouting the loose bricks as they were encountered during drilling.

\section{The Water Problem -}

One of the major problems with diamond drilling in existing structures is the water that is used to cool the diamonds and flush the cuttings out of the hole. In this case the water problem was far greater than had been anticipated. The bricklayers had taken great care to ensure that the inside and outside mortar joints were full and neatly pointed, but the inner joints were less carefully done. Water from the drill bit flowed along inside the wall and seeped out on the inside leaving a red stain everywhere. Plastic sheets and holes in the ceilings and floors were used to limit the extent of this water damage but it was difficult to control. Other problems associated with the water were mould growth on the inside walls and lime efflorescence on the outside surfaces. These were overcome by treating the inside walls with a fungicide prior to painting and by acid washing the outer surface.

Recent overseas developments of drilling foams may be worth investigati if water control is critical on future jobs of this type.

\section{Grouting -}

After flushing out the holes, reinforcing bars were placed and a $12 \mathrm{~mm}$ grout hose was fed down from the top of the hole. A grout with a water cement ratio of 0.45 was pumped into the bottom of the hole and the hose slowly withdrawn as the grout column rose.

No spacers were used to centre the bars in the holes. The fluid grout flowed around the bars and rapidly stiffened as the water was absorbed by the bricks. The absorption of water by the bricks also avoided the problems of bleedwater rising to the top of the grout column and grout leaking through cracks in the brickwork.

Most holes took some $50 \%$ more grout than the theoretical volume as the grout found its way into cavities in the brickwork. Near the corners where loose bricks had been encountered the holes required even more grout indicating that the brickwork had been extensively cracked.

SUMMARY:

The end result is considered to be very satisfactory and Church Officials and congregation were more than pleased at the unobtrusive nature of the strengthening work. This was achieved at a cost of just over $50 \%$ of a new building. We would certainly use this strengthening method again providing basic conditions of sound brickwork and the availability of a skilled drilling could be met.

The heavy roof had not yet been removed and this unfortunately has $b$

\section{9}

left for a second stage of the operation. With the heavy roof the Blenheim Borough Council have given the building a life evaluation of 30 years with five year reviews. Providing the heavy roof is removed the building will be given an unlimited life evaluation period.

\section{ACKNOWLEDGEMENTS :}

Section 6, Construction Aspects, was contributed by L.G. MCSaveney, B.E. M.I.P.E.N.Z. now Company Engineer, Fletcher Concrete Ltd.

The main contractors were T.H. Barnes and Co. Ltd of Blenheim, and the subcontractors for the drilling and grouting were the Stresscrete (Marl) Division of Fletcher Concrete Limited, in association with Longyear NZ Limited. These firms took a special interest in the project and ensured its successful completion.

The Blenheim Borough Council have pursued a policy for upgrading buildings and were most cooperative at all stages.

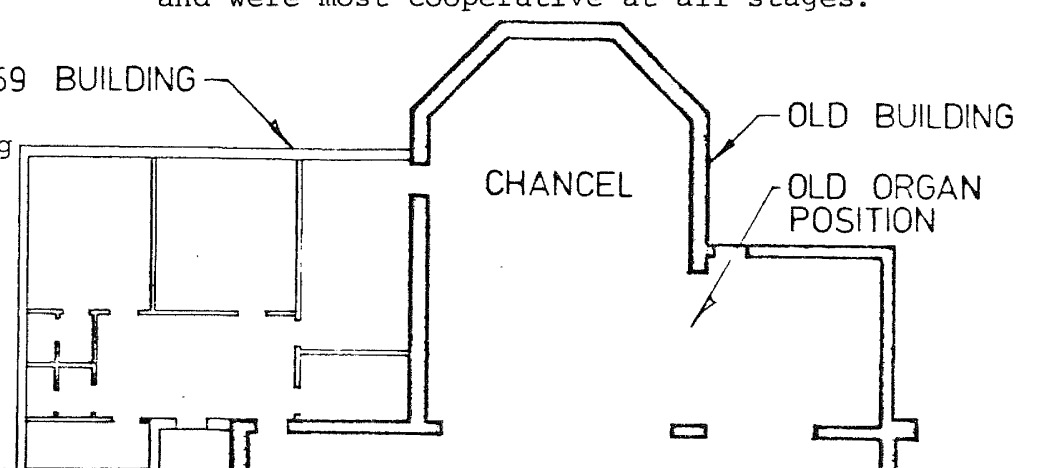



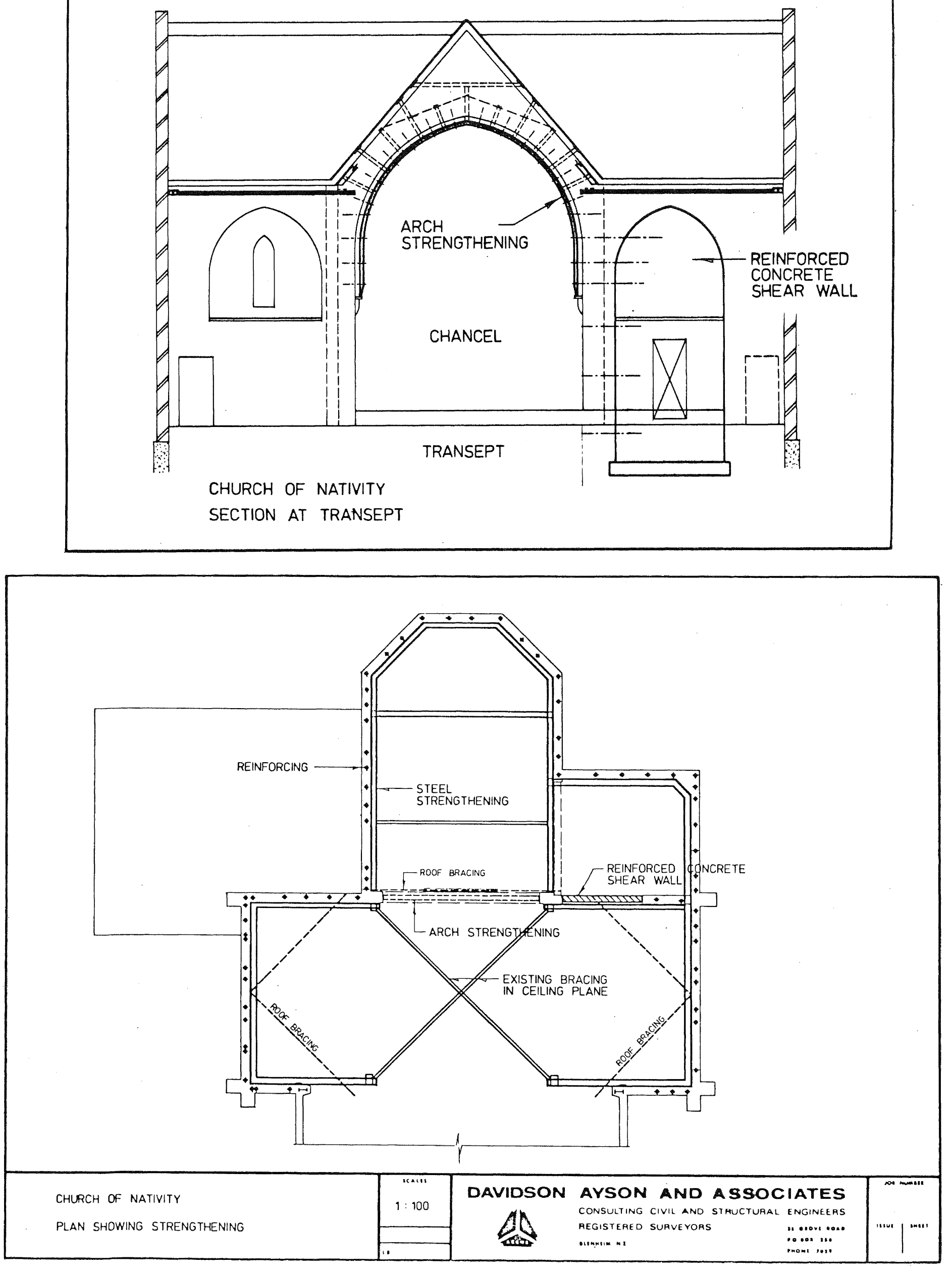

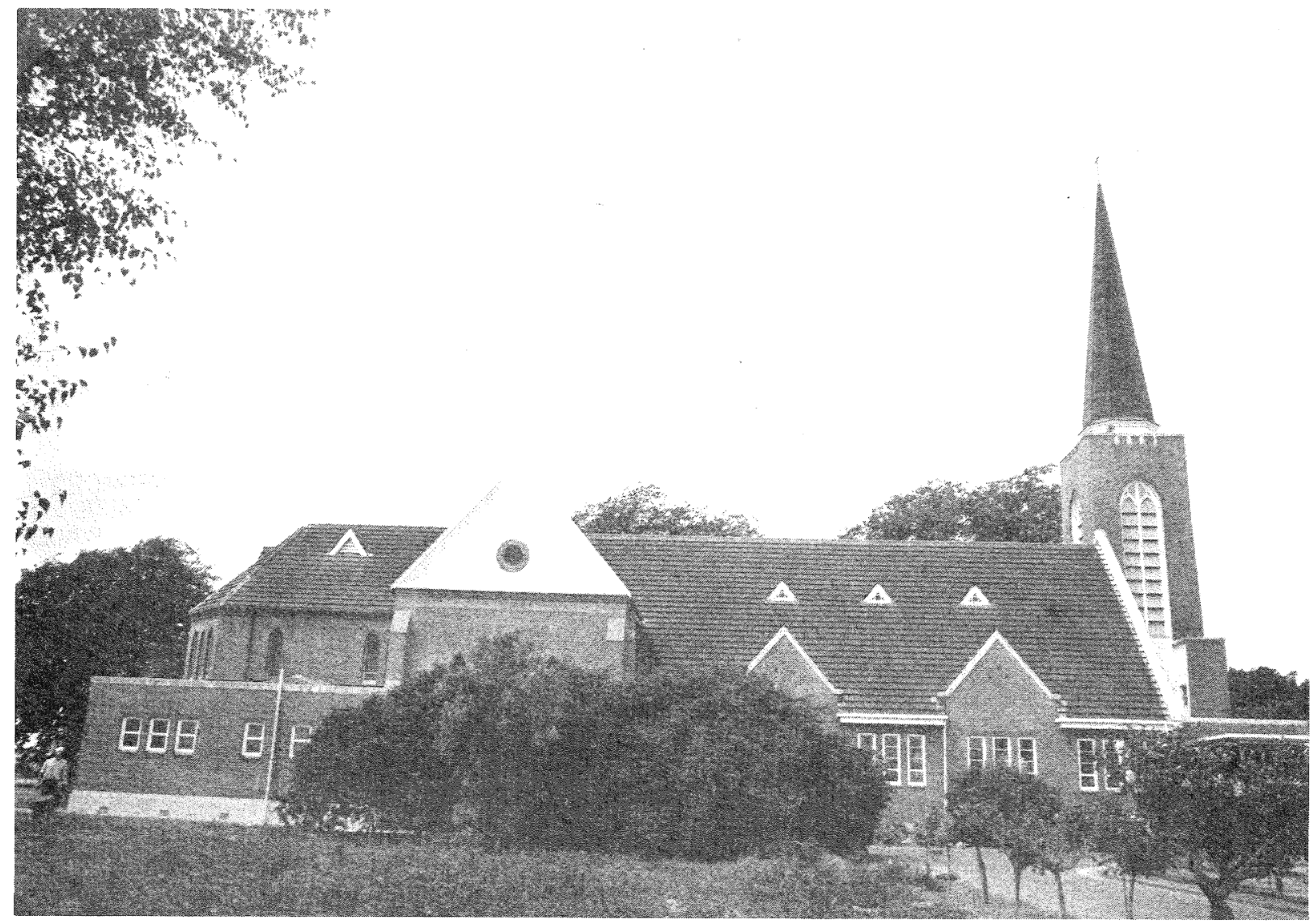

General View.

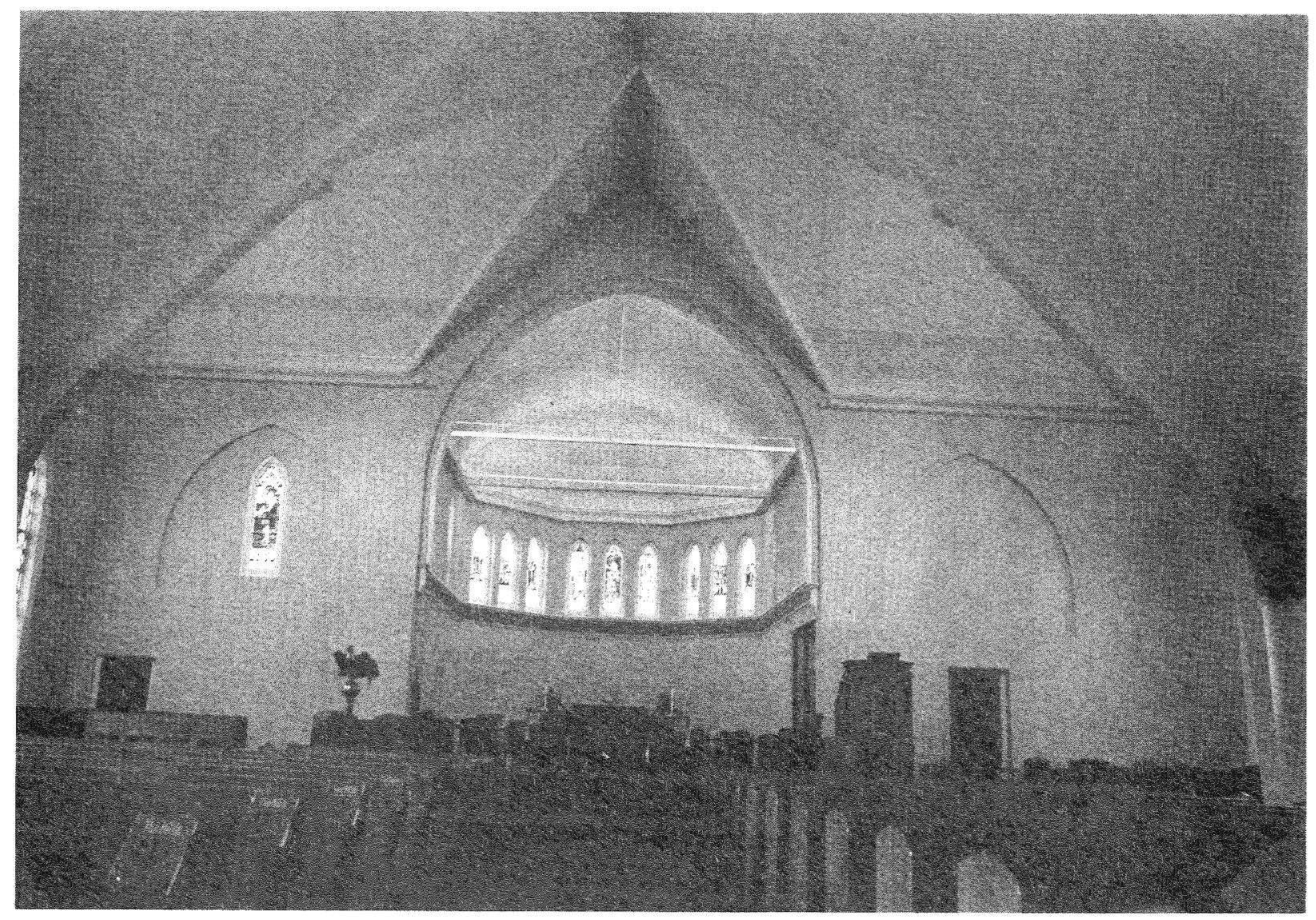

Interior as completed. 